\title{
RESPONSE OF RUNOFF IN NINGXIA SECTION OF YELLOW RIVER BASIN OF CHINA TO CLIMATE CHANGES
}

\author{
WANG, Z. P. ${ }^{1,2,4 *}-$ TIAN, J. C. ${ }^{1,3,4}-$ FENG, K. P. ${ }^{1,3,4}$ \\ ${ }^{1}$ College of Civil and Hydraulic Engineering, Ningxia University, Yinchuan 750021, China \\ ${ }^{2}$ School of Mathematics and Statistics, Ningxia University, Yinchuan 750021, China \\ ${ }^{3}$ Ningxia Research Center of Technology on Water-Saving Irrigation and Water Resources \\ Regulation, Yinchuan 750021, China \\ ${ }^{4}$ Engineering Research Center for the Efficient Utilization of Water Resources in Modern \\ Agricultural in Arid Regions, Yinchuan 750021, China \\ (phone: +86-13895005003) \\ *Corresponding author \\ e-mail:wzp_0416@163.com
}

(Received 23 $3^{\text {rd }}$ Feb 2019; accepted $3^{\text {rd }}$ May 2019)

\begin{abstract}
As one of the major water sources in Ningxia of China, it is of great importance to maintain healthy ecological environment of the Yellow River. In this essay, basin hydrological model is adopted to simulate the influences of prediction of climate changes on runoff in river basin, which is of great theoretical and realistic significance to flood and draught control plans as well as long-term exploitation and utilization of water resources in Ningxia Section of Yellow River Basin of China. Based on analysis of the changing characteristics of major climates and hydrological features in Ningxia Section of Yellow River Basin of China, distributed hydrological model SWAT (Soil and Water Assessment Tool) coupled with GIS is used in this study to simulate the yearly and monthly runoff volumes under 15 different climate changes, with the aim to explore the influences of climate changes to runoff. The results show that the runoff volume in the basin has negative correlation with the temperature but in positive correlation with the rainfall, and that the influence of the changes of rainfall in the basin on the runoff is greater than that of the temperature, which could provide basis for decision making of water resource management in Ningxia Section of the Yellow River Basin of China.
\end{abstract}

Keywords: SWAT model, climate scenes, simulation, temperature, rainfall

\section{Introduction}

As the environment in which human beings live, climate could affect human activities, which has been know by all. The influences of climate changes are comprehensive, multi-dimensional and multi-layered, with positive and negative influences co-existing. Generally, people concern more the negative influences. Global warming caused by carbon dioxide affects directly water supply and distribution in the world and has influenced the natural ecosystem in many areas of the world. Due to limited adaptability, natural ecosystem is easily to be destroyed severely and even irreversibly. Rainfall changes caused by climate warming is an essential factor to study the influences of potential climate on water supply, for rainfall is the fundamental source of fresh water on the earth. Water resources planning depends on mainly spacetime distribution of rainfall and soil water. In the future, rainfall distribution would change obviously on the warmed earth and rainfall in many areas located in semi-arid subtropical zone would increase. Because global warming could cause profound changes of the global climate system, the coadaptation established between mankind 
and the ecological environmental system would be affected and disturbed significantly; therefore, global changes, especially climate changes, have attracted great concerns from governments of the world and the public.

Certain irrational activities of human beings have caused global warming in the world, which results in finally frequent draughts, floods and other natural disasters. In the past several decades, the global climate has had inconvenient changes, among which global warming has become an undisputed fact. Since IPCC (Intergovernmental Panel on Climate Change) was found in 1988, it has completed five evaluation reports on global climate changes (IPCC, 2013), among which it was pointed out in the fifth evaluation report: the average global surface temperature in the world between 18802012 rose $0.85^{\circ} \mathrm{C}$. Comparing the middle and late 21 st century and the period from 1986-2005, the average global temperature will keep rising $1.0 \sim 2.0$ and $1.0 \sim 3.7^{\circ} \mathrm{C}$. According to the observation results in the past hundred years in China, the average surface temperature in China in the 20th century had rose $0.5 \sim 0.8^{\circ} \mathrm{C}$, which showed similar trend of global warming. Climate changes could affect various fields and could change the conditions of global water circulation, which could result in spatial and temporal redistribution of water resource. In recent years, due to climate changes and the increase of human activities, about $31 \%$ annual runoff of 145 major rivers in the world shows rising tendency (9\%) or descending tendency (22\%) (Walling and Fang, 2003). Runoff of many major rivers in China declines, especially that in Haihe Basion and the Yellow River Basin (Wang et al., 2010; Bao et al., 2012; Feng et al., 2016). In recent years, many areas had floods or draughts often (Kunkelet al., 1999; Lindner et al., 2010; Zhang et al., 2015). For example, draught occurred in downstream of the Yellow River Basin, floods occurred in the Yangtze River Basin and Songhua River area respectively in 1997 and 1998, which had caused immense damages(Xu et al., 2010). Therefore, it is of great significance for understanding hydrological changing mechanisms and relieving future draughts and floods to know the reasons of the runoff changes in the changing environment.

Climate changes and human activities are two essential factors that could affect runoff changes. Climate changes affect runoff mainly through rainfall and potential evaporation (Chien et al., 2013; Zhao et al., 2015). A great number of studies have shown that global warming will aggravate global hydrological circulation (Huntington, 2006; Milliman et al., 2008). It has been predicated by the observation data and climate model studies that climate warming could result in significant increase of rainstorms (Wu and Lau, 2016). Many studies have used GCM and hydrologic model to evaluate the influences of climate changes on runoff (Eisner et al., 2017; Teklesadik et al., 2017). However, climate simulation factors could also affect runoff changes. The experiment adopted various factors (such as GCM model, project stage, emission scenes, downscaling method and deviation correction) to show the predicted flow is an factor for the modeling and that it is unnecessary to take all factors into consideration but to keep the overall design balance (Ringius et al., 1996; Aamery et al., 2016). Li et al. (2013) used two rainfall-runoff models to simulate the yearly and monthly runoff of southeastern Tibetan Plateau under the historical and future conditions of climate changes. Coles et al. (2017) studied the influences of climate changes on the hillslope runoff in the north of the Great Plains. Besides, with the increase of the population and the urbanization (Kuang et al., 2016), human activities, such as land use/cover changes (Rahman et al., 2015; Zhang et al., 2017; Yhang et al., 2019), operation of dam and reservoir, water and soil conservation projects as well as direct taking of surface water 
and groundwater, all could cause great influences on water resources. Zhai et al. (2017) investigated the climates and runoff tendencies of seven typical basins in China from 1961 to 2014 and attributed the runoff change within three periods to climate changes and human activities of each basin. The problem of water resources has aroused concerns of various scholars; moreover, it has become the bottle-neck of economic development of many countries and areas. In recent years, many professional scholars have begun to study the influences of climate changes on water resources, which could provide scientific theoretical basis for rational development and utilization of water resources, disaster prevention and reduction, water loss and soil erosion as well as comprehensive planning of the basin and could offer relevant policy reference to the decision-makers.

In this paper, distributed hydrological model SWAT coupled with GIS is used in this study to simulate the yearly and monthly runoff volumes under 15 different climate changes, with the aim to explore the influences of climate changes to runoff, and it can provide decision-making basis for water resource management in the Ningxia Section of the Yellow River Basin of China.

\section{Material and methods}

\section{Overview of the research area}

The Yellow River enters the downstream of Zhongwei City, Ningxia province, running through the Yellow River irrigation area of Zhongning County, Qingtongxia City, Litong District, Lingwu City, Yongning County, Yinchuan City, Helan County, Pinluo County, Dawukou District and Huinong District and flowing in Inner Mongolia at Shizuishan. There are three hydrological stations along the mainstream of the Yellow River, i.e., Xiaheyan, Qingtongxia and Shizuishan hydrological stations. The Yellow River Basin within Ningxia is located in north latitude $36^{\circ} 0^{\prime} \sim 39^{\circ} 23^{\prime}$, east longitude $104^{\prime} 17^{\prime} \sim 107^{\prime} 39^{\prime}$, with the drainage area of $51400 \mathrm{~km}^{2}$. The geomorphic type is alluvial plain of Yellow River, where the terrain is flat with various ditches. The altitude is 1100 2500. It is arid region of temperate zone with abundant sunshine. The average annual sunshine hours are within $2750 \sim 2950 \mathrm{~h}$, the average annual wind speed is within $1.7 \sim 2.5 \mathrm{~m} / \mathrm{s}$. The temperature varies greatly, with abundant heat and longer frost-free period. The drainage basin belongs to continental climate, drought with less rainfall, with the average rainfall of $180 \sim 220 \mathrm{~mm}$. The inter-annual rainfall changes decrease from north to south gradually; the difference of average monthly rainfall in the Yellow River irrigation area is relatively obvious but the annual distribution is nonuniform; the changes of inter-annual rainfall in the central arid area and the south mountainous area are relatively mild, showing seasonal variation. The inter-annual rainfall in the basin is distributed unevenly; the dry and humid seasons are obvious; rainfall of July to September covers $60 \% \sim 70 \%$ of the annual total amount; the evaporation is high, with the annual amount of evaporation of $1100 \sim 1600 \mathrm{~mm}$. The types of land use are mainly lawn and farmland, covering respectively $33.74 \%$ and $48.76 \%$ of the basin area, the woodland covering $3.60 \%$, the water area covering $1.43 \%$, the urban and rural industrial and mining land and the residential land covering $1.46 \%$, and the unused land covering $11.01 \%$. 


\section{Model calibration}

SWAT (Soil and Water Assessment Tool) model was adopted as hydrological forecast model to simulate the hydrological circulation process in Ningxia section of the Yellow River Basin. This model could be used for short-term, middle-term and longterm hydrological forecast as well as for the evaluation of water resource regime in future climate scenarios. In the modeling process, the testing data of the meteorological and hydrological stations were taken as the input source to calibrate and test the model parameters. The simulation was based on the meteorological and hydrological data of Ningxia section from 1990 to 2012. With relative error $R_{g}$, correlation coefficient $R^{2}$ and Nash-Suttcliffe coefficient Ens as the standards, the sensitive parameters of the model were calibrated with the actually measured monthly runoff volumes within 2000 2006 and the model was validated with the actually measured monthly runoff volume within 2007-2012. The relative error $R_{\varepsilon}$ between the calibration period and the verification period was close to $10 \%$, the correlation coefficient $R^{2}$ and Nash-Suttcliffe coefficientEns were larger than 0.86 and 0.85 during the calibration period, with good simulationresults. This suggests that this model is applicable to hydrological simulation of Ningxia section of the Yellow River Basin and could be used for quantitative and qualitative study of the basin under future climate changes. The DEM map of study area see Fig. 1.

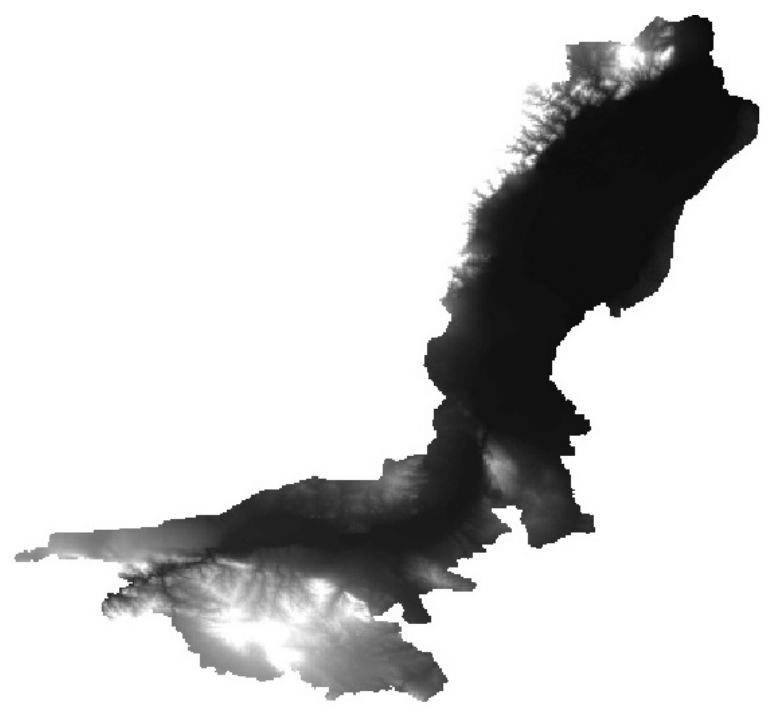

Figure 1. DEM Map of Ningxia Section of the Yellow River Basin

\section{Scene design of the climate changes}

There are various reasons for climate changes, of which natural climate change caused by human activities affecting directly or indirectly global atmosphere is the key one. Climate change is naturally to cause the change of water circulation, redistribution of water resources in time and space as well as the change of quantity of water resource, which could in turn affect the development of ecological environment and the social economy. Global climate warming could cause rise of the seal level, gradual drop of groundwater level, melting of glacier and frequent occurrence of extreme climates. In 
terms of hydrological circulation, climate change could change redistribution of water resources in time and space and could cause the changes of rainfall and evaporation, which could in turn affect the water balance of the overall basin. Rise of the temperature could accelerate the melting of glacier snow. Certainly, it could also affect other hydrological factors and then affect the runoff volumes of rivers as well as the hydrological process of the overall basin. Rainfall is the major influencing factor of water resource in the basin as well as the major water resource of the basin, that is, rainfall is the basis of the formation of runoff. Changes of rainfall plays significant roles in water resources quantity. It could influence directly water resources quantity of the basin and then the hydrological process of the basin.

Generally, there are two design methods of climate scenes: (1) Arbitrary scene setting: Based on the actual conditions of the study area, taking advantage of the interlocking combination of the supposed rainfall changes and the temperature rising scene, study the influences of climate changes on water resources with appropriate hydrological model. (2) Atmospheric circulation pattern (GCMs) method: This model forecasts the climate changes in the future based on the influences of different $\mathrm{CO}_{2}$ emissions on climate changes (Feng et al., 2016), and analyzes influences of climate changes on water resources by coupling with hydrological model. However, because the grid interval of the GCMs model data is larger, the spatial resolution is low and the confidence degree is not high when it is used to analyze the influences of climate changes on water resources. So, this essay adopts arbitrary scene setting to establish the scene of climate change in the study area.

Entering the 1980s, the major problems concerned by the human society in the world is no other than global climate changes. There are sufficient evidences to show that with the increase of $\mathrm{CO}_{2}$ and other greenhouse gases, the global climate is having sharp changes that have never had in history. It was pointed out in the fourth evaluation report of the first working group of Intergovernmental Panel on Climate Change (IPCC) that in the past 100 years from 1906 to 2005, the global climate became warm obviously and it was shown by the statistic results the surface temperature on the earth rose $0.74^{\circ} \mathrm{C}$. Especially, in the recent 50 years, the rising rate of the temperature was higher than the former 50 years, during which the temperature rose $0.65^{\circ} \mathrm{C}$; while 11 of the latest 12 years ranked in the 12 warmest years since 1850 (IPCC, 2013). In the past 100 years, the temperature in China rose $0.4 \sim 0.5^{\circ} \mathrm{C}$, slightly lower than the average of the world but in line with the general trend of climate changes. In the latest 50 years, the average temperature in summer in China has no obvious changes, but that in winter increased obviously, increasing $0.42^{\circ} \mathrm{C}$ every 10 years. Since 1985 , China has had continuously 16 nationwide warm winter, among which the winter in 1998 was the warmest, $1.4^{\circ} \mathrm{C}$ warmer. Scientists have made prediction of the global climate in the future 100 years based on population growth, the environmental condition, globalization, economic development and technological progress, the result of which suggested that by the end of the 21 st century, the average global temperature would increase $1.1 \sim 6.4^{\circ} \mathrm{C}$, the rainfall would transmit seasonally from south to north, among which the arid and semiarid areas would become drier with varying changing tendencies in different areas. Chinese scientist used different global climate patterns and regional climate patterns in China to study the climate changing scenes of China after $\mathrm{CO}_{2}$ is increased. Supposing atmospheric $\mathrm{CO}_{2}$ keeping increasing, it is expected the temperature would rise $1.68^{\circ} \mathrm{C}$ by $2020 \sim 2030 ; 2.22^{\circ} \mathrm{C}$ by 2050 ; it is predicted the temperature could reach $2.94^{\circ} \mathrm{C}$ in case the concentration of $\mathrm{CO}_{2}$ doubles and the warming amplitude in the north is higher than 
the south. Temperature in Northwest China could rise, $1.9 \sim 2.3^{\circ} \mathrm{C}$, rise $1.6 \sim 2.0^{\circ} \mathrm{C}$ in southwest and in Tibetan Plateau rise $2.2 \sim 2.6^{\circ} \mathrm{C}$. Rainfall shows rising tendency in many areas, with the south-eastern coast the largest, where the annual rainfall could increase $6.4 \% \sim 11 \%$ (Jiang et al., 2008).

Based on the above predictions of the global and Chinese climate changes, 15 different climate scenes are set in this essay to reflect the influences of climate changes on runoff. The established climate changes in the future are: Change of the temperature on the original bases are $0^{\circ} \mathrm{C},+1^{\circ} \mathrm{C}$ and $+2^{\circ} \mathrm{C}$, while the changes of the rainfall are respectively $-20 \%,-10 \%, 0 \%, 10 \%$ and $20 \%$ of the original. Specific combinations see Table 1.

Table 1. 15 different climate scene settings

\begin{tabular}{cc|ccccc}
\hline & \multicolumn{5}{|c}{ Rainfall changes } \\
\cline { 3 - 7 } & & $\mathrm{P} \times(1-20 \%)$ & $\mathrm{P} \times(1-10 \%)$ & $\mathrm{P}$ & $\mathrm{P} \times(1+10 \%)$ & $\mathrm{P} \times(1+20 \%)$ \\
\hline \multirow{2}{*}{$\begin{array}{c}\text { Temperature } \\
\text { changes }\end{array}$} & $\mathrm{T}$ & $\mathrm{A} 11$ & $\mathrm{~A} 12$ & $\mathrm{~A} 13$ & $\mathrm{~A} 14$ & $\mathrm{~A} 15$ \\
& $\mathrm{~T}+1^{\circ} \mathrm{C}$ & $\mathrm{A} 21$ & $\mathrm{~A} 22$ & $\mathrm{~A} 23$ & $\mathrm{~A} 24$ & $\mathrm{~A} 25$ \\
& $\mathrm{~T}+2^{\circ} \mathrm{C}$ & $\mathrm{A} 31$ & $\mathrm{~A} 32$ & $\mathrm{~A} 33$ & $\mathrm{~A} 34$ & $\mathrm{~A} 35$ \\
\hline
\end{tabular}

\section{Results and discussion}

The actually measured temperatures and rainfall amounts are increased and decreased accordingly based on the above 15 scenes to generate the meteorological data corresponding to 15 climate scenes. Based on SWAT model established in Model calibration Section, the changed meteorological data are input in SWAT model to simulate the average monthly runoff volumes of tributary station and the simulation results of different scenes are as shown in Table 2.

Table 2. Runoff simulation of 15 different climate scenes

\begin{tabular}{cc|c|ccccc}
\hline & & \multicolumn{5}{|c}{ Rainfall changes } \\
& & & $\mathrm{P} \times(1-20 \%)$ & $\mathrm{P} \times(1-10 \%)$ & $\mathrm{P}$ & $\mathrm{P} \times(1+10 \%)$ & $\mathrm{P} \times(1+20 \%)$ \\
\cline { 2 - 7 } Temperature & Average yearly & $\mathrm{T}$ & 7568.3 & 8567.1 & 9683.2 & 10987.5 & 12334.9 \\
runoff (ten & $\mathrm{T}+1^{\circ} \mathrm{C}$ & 7002.4 & 8011.7 & 9234.9 & 10468.8 & 11975.3 \\
changes & thousand $\left.\mathrm{m}^{3}\right)$ & $\mathrm{T}+2^{\circ} \mathrm{C}$ & 6253.6 & 7498.8 & 8806.7 & 10023.4 & 11334.4 \\
\cline { 2 - 7 } & Variation amount & $\mathrm{T}$ & -2114.7 & -1115.9 & 0.2 & 1304.5 & 2651.9 \\
& $($ ten thousand & $\mathrm{T}+1^{\circ} \mathrm{C}$ & -2680.6 & -1671.3 & -448.1 & 785.8 & 2292.3 \\
& $\left.\mathrm{~m}^{3}\right)$ & $\mathrm{T}+2^{\circ} \mathrm{C}$ & -3429.4 & -2184.2 & -876.3 & 340.4 & 1651.4 \\
\cline { 2 - 7 } & \multirow{2}{*}{$\begin{array}{c}\text { Changing rate } \\
(\%)\end{array}$} & $\mathrm{T}+1^{\circ} \mathrm{C}$ & $-21.8 \%$ & $-11.5 \%$ & $0.0 \%$ & $13.5 \%$ & $27.4 \%$ \\
& $\mathrm{~T}+2^{\circ} \mathrm{C}$ & $-35.4 \%$ & $-17.3 \%$ & $-4.6 \%$ & $8.1 \%$ & $23.7 \%$ \\
\hline
\end{tabular}

It could be seen from Table 2 that the runoff in Ningxia section of Yellow River Basin changes with the temperature and the rainfall in the following rules:

(1) The runoff volume in the basin is in negative correlation with the temperature and in positive correlation with the rainfall. With the temperature unchanged and the rainfall increasing $10 \%$, the runoff increases 1304.5 ten thousand $\mathrm{m}^{3}$, increasing $13.5 \%$; with the temperature unchanged and the rainfall increasing 20\%, the runoff increases 2651.9 ten thousand $\mathrm{m}^{3}$, increasing $27.4 \%$, with the rainfall unchanged but the temperature increasing $1^{\circ} \mathrm{C}$, the runoff decreases 448.1 ten thousand $\mathrm{m}^{3}$, decreasing $4.6 \%$; with the 
rainfall unchanged by the temperature increasing $2^{\circ} \mathrm{C}$, the runoff decreasing 876.3 ten thousand $\mathrm{m}^{3}$, decreasing $9.0 \%$. It could be seen thus rise of temperature could cause decrease of the runoff, the reason for which is rise of temperature could make the amount of evaporation greater; while increase of rainfall could make the runoff increase and the reason is that increase of rainfall could make the surface runoff yield increase.

(2) Rainfall changes in the basin have greater influences on the runoff than temperature. With the rainfall unchanged but the temperature increasing $2^{\circ} \mathrm{C}$, the runoff decreases 876.3 ten thousand $\mathrm{m}^{3}$, decreasing $9.0 \%$, which is in small scale; with the temperature unchanged by the rainfall increasing $20 \%$, the runoff increases 2651.9 ten thousand $\mathrm{m}^{3}$, increasing $27.4 \%$, which is in large scale.

Runoff simulation under the condition with the rainfall unchanged but the temperature changed is as shown in Fig. 2 and the runoff simulation under the condition with the temperature unchanged but the rainfall changed is as shown in Fig. 3.

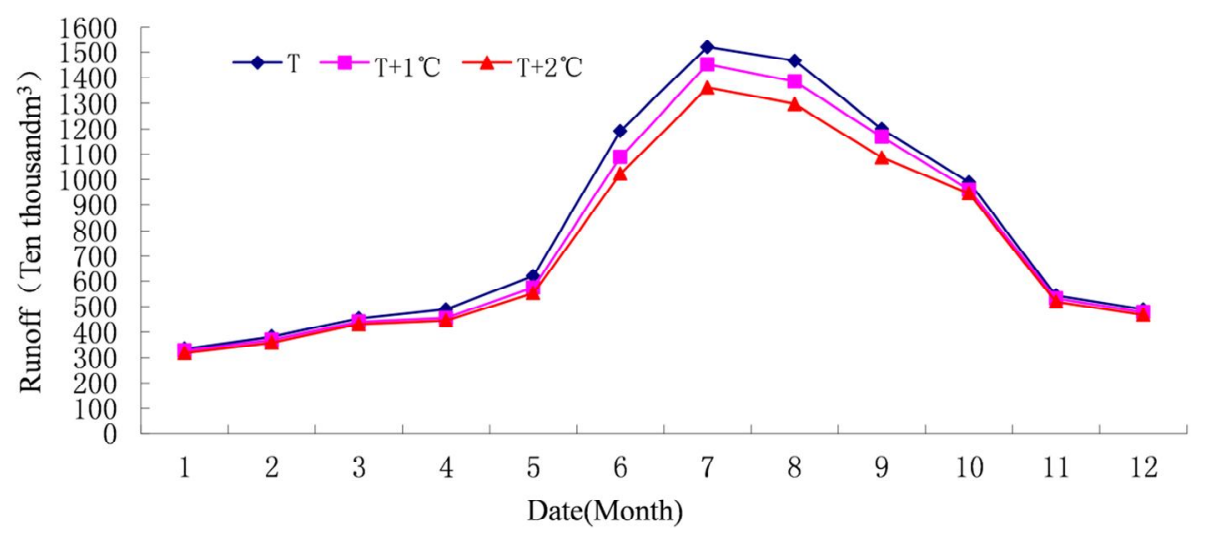

Figure 2. Comparison between runoff volumes in climate scenes with the rainfall unchanged but the temperature changed

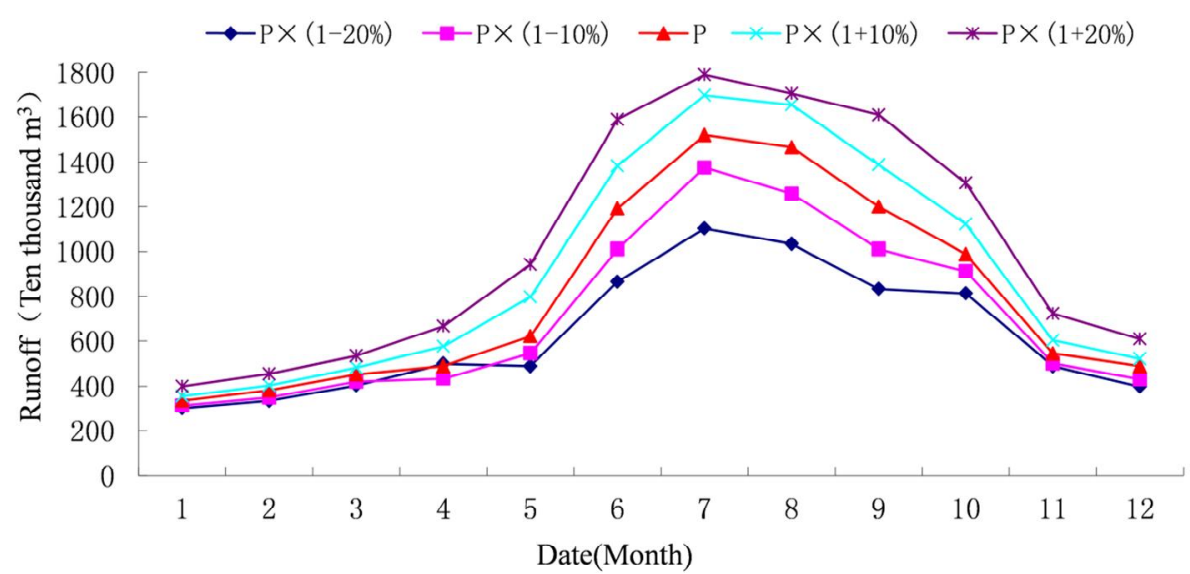

Figure 3. Comparison between runoff volumes in climate scenes with the temperature

It could be seen from Fig. 2 with the rainfall unchanged, the runoff volumes show decreasing tendency. When the temperature rises, the evaporation amount would also increase so that the runoff decreases. It could be seen from Fig. 3 with the temperature unchanged, the monthly runoff volumes and the rainfall changes have the same 
tendency, which begins to increase in spring and increases the most in summer; however, it decreases gradually in autumn but with the smallest increase in winter.

\section{Conclusion}

Distributed hydrological model SWAT coupled with GIS is used in this study to simulate the yearly and monthly runoff volumes under 15 different climate changes, with the aim to explore the influences of climate changes to runoff. The results show that the runoff volume in the basin has negative correlation with the temperature but in positive correlation with the rainfall, and that the changes of temperature has greater influences on the changes of rainfall but has little influences on the runoff. Its prediction of climate warming in the future has high credibility but the prediction of rainfall increase in the future is of certain degree of uncertainty; however, the influence of rainfall on runoff volume is more significant than that of temperature. Generally, it could provide some scientific basis for management and utilization of river basin water resources.

Acknowledgements. The study was completed with the support of the First-class Major Foundation of Ningxia Institutions of High Education in China. (NXYLXK2017A03).

\section{REFERENCES}

[1] Aamery, N. A., Fox, J. F., Snyder, M. (2016): Evaluation of climate modeling factors impacting the variance of streamflow. - J. Hydrol. 542: 125-142.

[2] Bao, Z. X., Zhang, J. Y., Wang, G. Q., Fu, G. B., He, R. M., Yan, X. L., Jin, J. L., Liu, Y. L., Zhang, A. J. (2012): Attribution for decreasing stream flow of the Haihe River basin, northern China: climate variability or human activities? - J. Hydrol. 460-461: 117-129.

[3] Chien, H. C., Yeh, P. J. F., Knouft, J. H. (2013): Modeling the potential impacts of climate change on streamflow in agricultural watersheds of the Midwestern United States. - J. Hydrol. 491: 73-88.

[4] Coles, A. E., Conkey, B. G. M., McDonnell, J. J. (2017): Climate change impacts on hillslope runoff on the northern Great Plains, 1962-2013. - Journal of Hydrology 550: 538548.

[5] Eisner, S., Flörke, M., Chamorro, A., Daggupati, P., Donnelly, C., Huang, J., Hundecha, Y., Koch, H., Kalugin, A., Krylenko, I., Mishra, V. (2017): An ensemble analysis of climate change impacts on stream flow seasonality across 11 large river basins. - Clim. Change 141(3): 1-17.

[6] Feng, X. M., Cheng, W., Fu, B. J., Lu, Y. H. (2016): The role of climatic and anthropogenic stresses on long-term runoff reduction from the Loess Plateau, China. - Sci. Total Environ. 571: 688-698.

[7] Huntington, T. G. (2006): Evidence for intensification of the global water cycle: review and synthesis. - J. Hydrol. 319(1-4): 83-95.

[8] IPCC. (2013): Working group i contribution to the IPCC fifth assessment report, climate change: the physical science basis: summary forpolicymakers[R/OL]. - http://www. climatechange2013. org /images /uploads /WGIAR5SPM_Approved27Sep2013. Pdf, 2013-10-28.

[9] IPCC: IPCC Fourth Assessment Report (AR4). - http: //ipcc-wg1. ucar. edu/wg1 /wg1report. Htm, 1200. 
[10] Jiang, Z. H., Zhang, X., Wang, J. (2008): IPCC-AR4 Estimation of China's 21st Century Climate Change by IPCC-AR4 Model. - Geographic research 27(4): 787-799.

[11] Kuang, W., Liu, J., Dong, J., Chi, W., Zhang, C. (2016): The rapid and massive urban and industrial land expansions in China between 1990 and 2010: a CLUD-based analysis of their trajectories, patterns, and drivers. Landsc. - Urban Plan. 145: 21-33.

[12] Li, F., Zhang, Y., Xu, Z., Teng, J., Liu, C., Liu, W., Mpelasoka, F. (2013): The impact of climate change on runoff in the southeastern Tibetan Plateau. - Journal of Hydrology 505: 188-201.

[13] Lindner, M., Maroschek, M., Netherer, S., Kremer, A., Barbati, A., Garcia-Gonzalo, J., Seidl, R., Delzon, S., Corona, P., Kolstrom, M., Lexer, M. J., Marchetti, M. (2010): Climate change impacts, adaptive capacity, and vulnerability of European forest ecosystems. - For. Ecol. Manag. 259(4): 698-709.

[14] Milliman, J. D., Farnsworth, K. L., Jones, P. D., Xu, K. H., Smith, L. C. (2008): Climatic and anthropogenic factors affecting river discharge to the global ocean, 1951-2000. Glob. Planet. Chang. 62(3-4): 187-194.

[15] Rahman, K., da Silva, A. G., Tejeda, E. M., Gobiet, A., Beniston, M., Lehmann, A. (2015): An independent and combined effect analysis of land use and climate change in the upper Rhone River watershed, Switzerland. - Applied Geography 63: 264-272.

[16] Ringius, L., Downing, T. E., Hulme, M. (1996): Climate change in Africa: Issue and challenges in Agriculture and water for Sustainable envelopment. - CICERO Report[R]. University of Oslo, Norway, 151.

[17] Teklesadik, A. D., Alemayehu, T., van Griensven, A., Kumar, R., Liersch, S., Eisner, S., Tecklenburg, J., Ewunte, S., Wang, X. (2017): Inter-model comparison of hydrological impacts of climate change on the Upper Blue Nile basin using ensemble of hydrological models and global climate models. - Clim. Change 1-16.

[18] Walling, D. E., Fang, D. (2003): Recent trends in the suspended sediment loads of the world's rivers. - Glob. Planet. Chang. 39(1-2): 111-126.

[19] Wang, J. H., Hong, Y., Gourley, J., Adhikari, P., Li, L., Su, F. G. (2010): Quantitative assessment of climate change and human impacts on long-term hydrologic response: a case study in a sub-basin of the Yellow River, China. - Int. J. Climatol. 30(14): 2130-2137.

[20] Wu, H.-T. J., Lau, W. K. M. (2016): Detecting climate signals in precipitation extremes from TRMM (1998-2013)-increasing contrast between wet and dry extremes during the "global warming hiatus". - Geophys. Res. Lett. 43(3): 1340-1348.

[21] Xu, K. H., Milliman, J. D., Xu, H. (2010): Temporal trend of precipitation and runoff in major Chinese Rivers since 1951. - Glob. Planet. Chang. 73(3-4): 219-232.

[22] Yang, W., Long, D., Bai, P. (2019): Impacts of future land cover and climate changes on runoff in the mostly afforested river basin in North China. - Journal of Hydrology 570: 201-219.

[23] Zhai, R., Tao, F. (2017): Contributions of climate change and human activities to runoff change in seven typical catchments across China. - Science of the Total Environment (605-606): 219-229.

[24] Zhang, Y. Q., You, Q. L., Lin, H. B., Chen, C. C. (2015): Analysis of dry/wet conditions in the Gan River Basin, China, and their association with large-scale atmospheric circulation. - Glob. Planet. Chang. 133: 309-317.

[25] Zhang, L., Karthikeyan, R., Bai, Z. K., Srinivasan, R. (2017): Analysis of stream flow responses to climate variability and land use change in the Loess Plateau region of China. - CATENA 154: 1-11.

[26] Zhao, Y., Zou, X., Gao, J., Xu, X., Wang, C., Tang, D., Wang, T., Wu, X. (2015): Quantifying the anthropogenic and climatic contributions to changes in water discharge and sediment load into the sea: a case study of the Yangtze River, China. - Sci. Total Environ. 536: 803-812. 